\title{
Novel DPP-IV-resistant Analogs of GLP-1: The $N$-terminal Extension of GLP-1 by a Single Amino Acid
}

\author{
Ji-Yeon Oh, ChangWoo Lee, ${ }^{+}$Sei-Heon Jang, ${ }^{\dagger}$ Seung-Bum Yoo, ${ }^{\ddagger}$ and Hye-Shin Chung ${ }^{-}$ \\ Department of Biotechnologv. Hannam University, Daejeon $305-811$. Korea. 'E-mail: hschungähnu.kr \\ Department of Molecular Biologv. Daegu Liniversity, Gyeongsan 712-714, Korea \\ Alteogen Inc., Bioventure Town, Daejeon 305-812, Korea \\ Received Juty 28, 2009, Accepted Atgust 28, 2009
}

Key Words: Glucagon-like peptide-1, Dipeptidyl peptidase IV. Fc fusion, Type 2 diabetes

Glucagon-like peptide-1 (GLP-1) is an incretin hormone produced from intestinal $L$ cells of the gut and plays an important role in glucose-dependent insulin secretion. suppression of glucagon secretion. proliferation of pancreatic $\beta$-cells, and inhibition of food intake. 'The short half-life of GLP-1 $\left(\mathrm{t}_{1: 2}<\right.$ 2 minutes) resulted from degradation by dipeptidyl peptidase IV (DPP-IV). however. has stymied the application of GLP-1 for the treatment of insulin-resistant type 2 diabetes. ${ }^{\text {E Exendin-4. }}$. which is derived from saliva of a lizard Gila monster with $\sim 53 \%$ sequence homology with GLP-I, has Gly in position 2 rather than Ala. as is the case in GLP-1. Thus. exendin-t is resistant to the cleavage by DPP-IV and has a half-life of approximately 30 minutes after intravenous administration and $2 \cdot 3$ hours after subcutaneous admunistration in humans. ${ }^{3.4}$

Previous research has been focused on the development of long-acting GLP-1 mimetics or DPP-IV inlibitors. A number of studies were reported on DPP-IV-resistant GLP-I analogs with chemucal modification ${ }^{5.6}$ or amino acid substitution. ${ }^{7.12}$ in which the latter largely relied upon substitutions of amino acid in the N-terninal region in GLP-I to evade the proteolytic degradation by DPP-IV. In addition, efforts to prolong the half-life of GLP-1 by attaching macromolecules such as albumin or immunoglobulin heavy chains (IgG-Fc). which are widely found in senum have been sought. For example. albumin fusion to GLP-1 was shown to activate GLP-1 receptor-dependent signaling pathways in baby hamster kidney cells. ${ }^{13}$ The fusion of mouse IgG-Fc to human GLP-1 (GLP-I/IgG-Fc) increased the half-life of GLP-1 in mouse. ${ }^{14}$

In this study we sought to elucidate whether the N-terminal extension of GLP-l by a single amino acid. Ala or Gly, evades the degradation by DPP-IV using 7-amino-4-methylcoumarin (AMC)-conjugated tripeptide (Ala-His-Ala-AMC or Gly-HisAla-AMC). We further examined whether the N-terminal modified GLP-1/IgG-Fc fision proteins could induce the expression of insulin receptor substrate-2 (IRS-2) in rat pancreatic $\beta$ cells.

Many previous attempts to synthesize DPP-IV-resistant GLP-1 analogs have been focused on mutations of amino acids in the GLP-1 sequence. We constnicted GLP-1/IgG-Fc fusion constructs with the N-terminal extension of GLP-l by a single amino acid. Ala or Gly in the pSGHV0 vector. $6 \times$ His tag followed by an enterokinase recognition sequence, AspAsp-Asp-Asp-Ly's. were localized prior to the N-terninal end of GLP-1. The recombinant GLP-1//gG-Fc fusion protein transiently expressed in $\mathrm{CHO}-\mathrm{Kl}$ cells were secreted into medium, suggesting that the protein is folded properly. The recombinant GLP-1/IgG-Fc fusion protein was successfully purified using a 5-1mL HisTrap column on FPLC (see Fig. 1A). The GLP-1/IgG-Fc was eluted in $100 \cdot 200 \mathrm{mM}$ imidazole

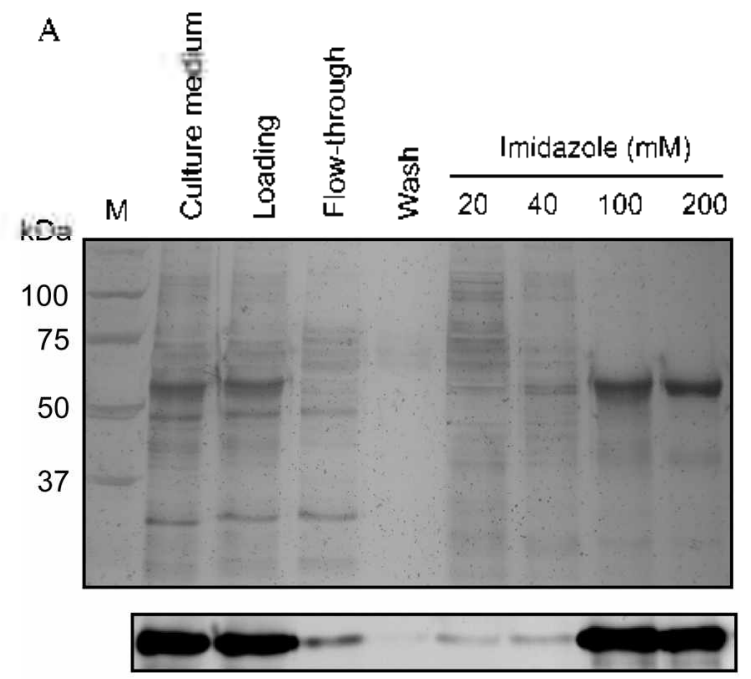

IB: GLP-1

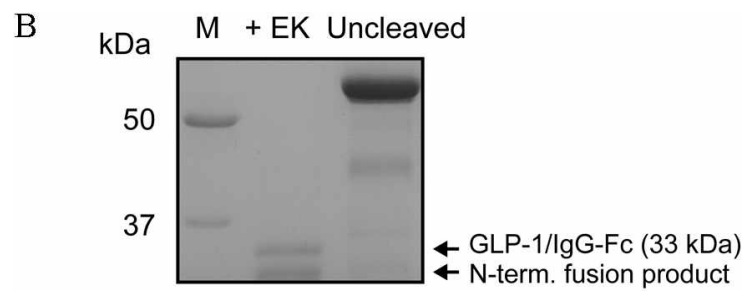

Figure 1. Expression and purification of GLP-1//gG-Fe fusion protein. (A) GLP-1/LgG-Fc tusion proteins were expressed in $\mathrm{CHO}-\mathrm{K} l$ cells. The 3,6, 10-days conditioned medium were pooled and purified using a 5-mL His Trap columu on FPLC. Proteins separated by SDSPAGE were stained with silver nitrate (upper panel) and identified by immunoblotting with anti-GLP-l-antibody (lower panel). M. marker. M.W. of tusion protein is $58 \mathrm{kDa}$. (B) Cleavage of the fusion protein by enterokinase. The purified fusion proteins were pooled and concentrated followed by treatment with enterokinase for 16 hour at $25^{\circ} \mathrm{C}$. M, marker, Fusion protein appears as a $33 \mathrm{kD}$ a atter enterokinase treatment. 

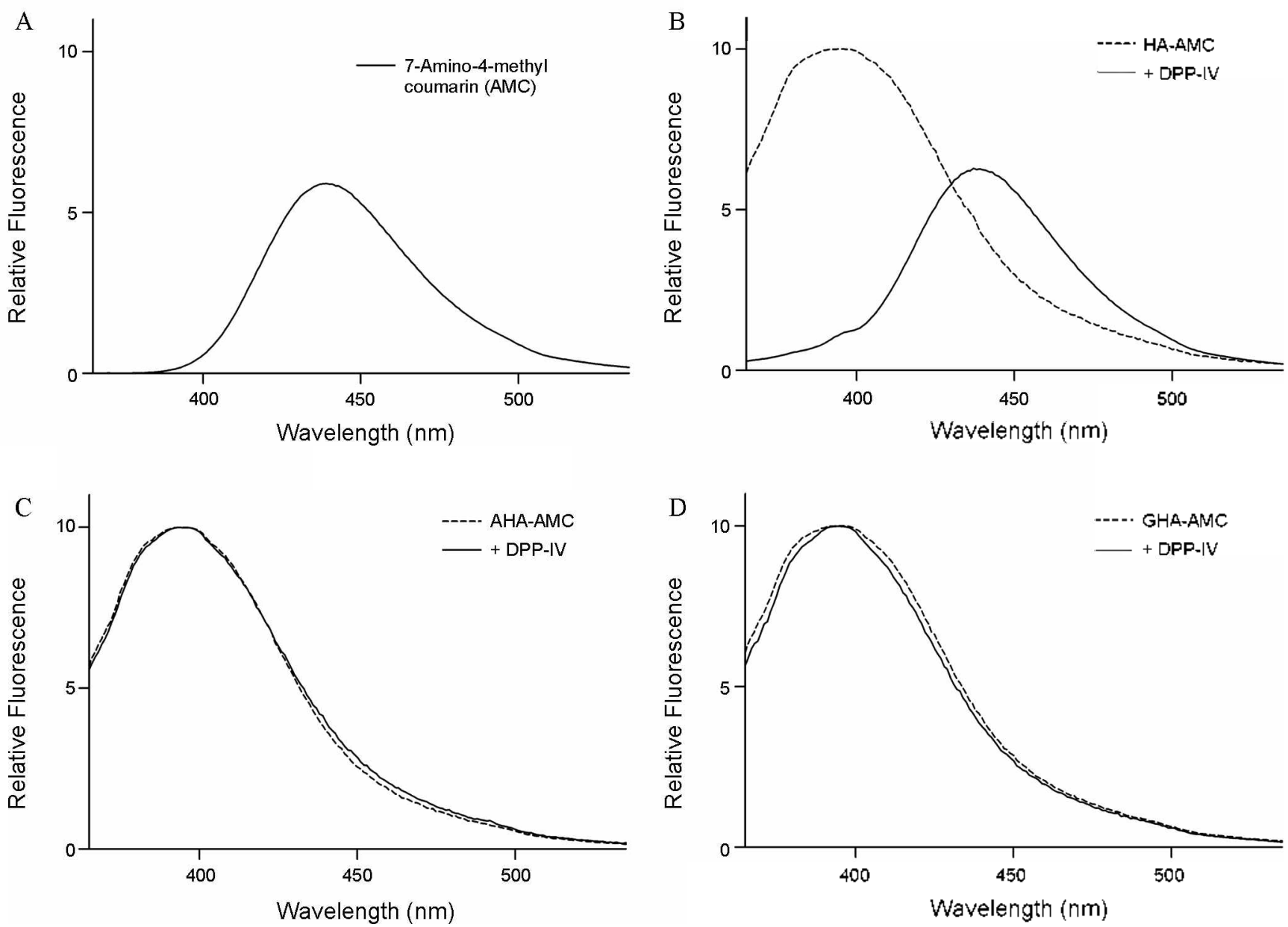

Figure 2. DPP-IV degradation assay. His-Ala (HA)-, Ala-His-Ala (AHA)- and Gly-His-Ala (GHA)-conjugated AMC were synthesized, respectively. AMC-conjugated peptides were incubated in the absence or presence of DPP-IV for $1 \mathrm{hr}$ at $37^{\circ} \mathrm{C}$. The fluorescence change was measured between $365-535 \mathrm{~mm}$ upon excitation at $350 \mathrm{~mm}$. (A) AMC only, (B) HA-AMC, (C) AHA-AMC, (D) GHA-AMC.

concentration. suggesting that the fusion protein bound to the nickel resion with a high affinity. The fusion protein appeared on the SDS gel with a molecular weight of $58 \mathrm{kDa}$. Following buffer exchange. the enterokinase recognition sequence was cleaved off by enterokinase at $25^{\circ} \mathrm{C}$ (see Fig. lB). Enterokinase cleaves the $\mathrm{C}$-terminal side of the recognition sequence allowing complete removal of affinity tag sequences. Recombinant GLP-1/IgG-Fe fusion protein upon treatment of enterokinase appeared on the SDS gel as a $33 \mathrm{kDa}$ band. The enterokinase enzyme was removed by protein A affinity column chromatography

Previously high-performance liquid chromatography and mass spectrometry have been used for the identification of cleaved GLP-1 fragments upon DPP-IV treatment. ${ }^{2.15}$ In this study, we utilized the fluorescence change of AMC-conjugated peptides as a measure to examine if the $\mathrm{N}$-terminal extension of GLP-1 by a single amino acid confers resistance to degradation by DPP-IV. The enzy me DPP-IV cleaves the N-tenminal dipeptide of substrates. especially after amino acid Pro or Ala. ${ }^{\text {lo }}$ Native His-Ala-AMC and N-terminal extended Ala-HisAla-AMC and Gly-His-Ala-AMC were sy'nthesized, respectively. It is expected that there would be no change of fluorescence if either of the tripeptides is resistant to DPP-IV. AMC itself showed its naximal emission at $440 \mathrm{~nm}$ upon excitation at $350 \mathrm{~mm}$ (see Fig. 2A). The fluorescence emission from AMC-conjugated peptides was blue-shifted compared to AMC. Upon treatment of DPP-IV for 1 hour at $37^{\circ} \mathrm{C}$. the fluorescence enuission from $\mathrm{His}-\mathrm{Ala}-\mathrm{AMC}$ was restored to the normal spectrum of AMC (see Fig. 2B). suggesting that the peptide bond between His-Ala and AMC was cleaved off by DPP-IV. However, the treatment of DPP-IV had no effect on the fluorescence emission of Ala-His-Ala-AMC or Gly-HisAla-AMC (see Fig. 2C and 2D), indicating that the peptide bond between the tripeptides and AMC is resistant to DPP-IV action.

Next. we exanined the expression of IRS-2 in insulin-producing rat INS-1 cells to see the GLP- $1 / \mathrm{IgG}-\mathrm{Fc}_{\mathrm{c}}$ fusion protein has retained its biological activity. The IRS-2 branch of insulin and insulin-like growth factor signaling pathways strongly promote $\beta$-cell growth and survival. which is essential for compensatory $\beta$ cell function during physiological or metabolic stress. "GLP-I induced 2-fold $(2.0 \pm 0.4)$ increase of IRS-2 protein expression (see Fig. 3). Upon treatment of wild-type GLP-1/IgG-Fc fusion protein. the expression of IRS-2 protein was increased 1.6 -fold $(1.6 \pm 0.1), 20 \%$ lower than the induction of IRS-2 by GLP-1. The modified A- and 


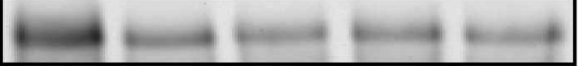

IB: IRS-2

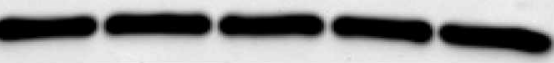

IB: GAPDH

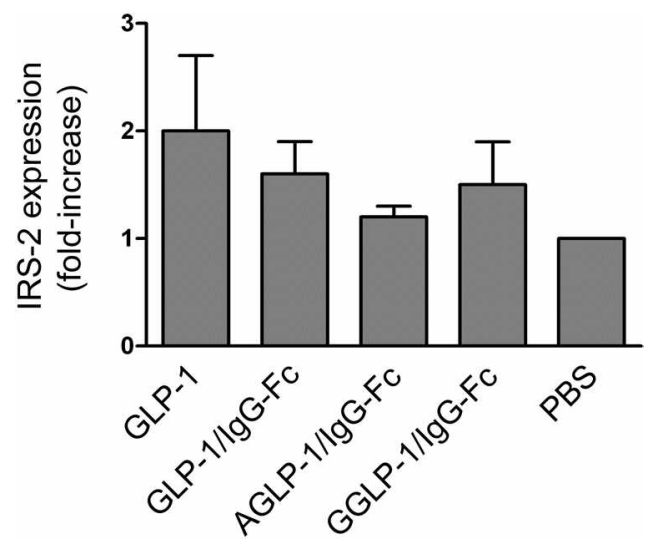

Figure 3. Induction of IRS-2 protein. Rat insulinoma INS-1 cells grown in 24-well plate were treated with native GLP-1, GLP-1/ IgG-Fc, Ala-GLP-1//gG-Fe and Gly-GLP-1/IgG-Fc, respectively for 7 hours. Fusion proten was identified by polyclonal antibody to IRS-2. Experiments were repeated three times. Bar graph shows the band intensity of IRS-2 over PBS-treated sample as mean $\pm \mathrm{S}$. $\mathrm{D}$.

G-GLP-1/IgG-Fc fusion protein both showed 1.2-fold (1.2 \pm $0.1)$ and 1.5 -fold $(1.5 \pm 0.2)$ increase of IRS-2 expression. respectively. Addition of Ala to the dipeptide led to $20 \%$ lower IRS-2 expression than the addition of Gly. Our data suggests that the N-terminal extension of GLP-1//gG-Fc fusion protein by a single amino acid is functionally active. Ligand binding to the GLP-1 receptor occurs in two steps: the C-terminial region of GLP-I initially binds to the receptor and a secondary contact occurs between the N-terminal region of GLP-1 and the transmembrane and extracellular loops of the GLP-1 receptor for receptor activation. ${ }^{18.19}$ Thus. it is believed that the decreased IRS-2 expression compared to native GLP-1 is in part due to structural hindrance in GLP-l binding to the GLP-1 receptor by Fe fusion.

In conclusion. we demonstrated that the AMC-conjugated tripeptides were resistant to degradation by DPP-IV. Furthermore, both of the N-terminal extended GLP-1/IgG-Fo fusion proteins by a single amino acid. Ala or Gly were functionally active by inducing the expression of IRS-2 in rat insulinoma INS-I cells. Mechanisms of fusion protein binding to the GLP-1 receptor and signal generation need to be further elucidated in the future

\section{Experimental Section}

Materials. Human glucagon cDNA was purchased from OriGene Technologies. Inc. (USA). Human GLP-1 was purchased from Sigma (USA). The pSGHV0 vector was kindly provided by Jong-Bok Yoon (Yonsei University, Seoul.
Korea) ${ }^{2}{ }^{2}$ The pOPGFc plasnuid containing human IgG $\gamma-\mathrm{Fc}_{\mathrm{c}}$ was kindly provided by Young-Chul Sung (Pohang University of Science and Technology. Pohang. Korea). AMC-conjugated three peptides (His-Ala-AMC, Ala-His-Ala-AMC, and Gly-His-Ala-AMC) were synthesized at Peptron (Korea). Enterokinase was purchased from Invitrogen (USA). Monoclonal antibody to GLP-I and polyclonal antibody to IRS-2 were purchased from Santa Cruz Biotechnology. Inc (USA). All other reagents, unless stated othenwise, were from Sigma (USA).

GLP-1/IgG-Fc fusion plasmid construction. The human IgG $\gamma$-hinge $F_{c}$ sequence encoding 234 amino acids was amplified from the pOPGFc plasnid by polymerase chain reaction (PCR) with the following primers: the forward primer was 5'-GGATCCgctagcGAGCCCAAATC-3' (BamHI site underlined, linker sequence in small letters, and the N-terminal region of IgG-Fc in boldface type) and the reverse primer was 5'-GCGGCCGCTCATTTACCCGGAGA-3' (NotI site underlined and the $\mathrm{C}$-temminal region of $\mathrm{IgG}-\mathrm{Fc}$ in boldface type). The PCR product was sequenced and subcloned into the BanHI and NotI sites of the pSGHVo vector. generating a construct of pSGHV0-Fc. Human GL.P-l was amplified from human glucagon CDNA by PCR with the following primers; the forward primer was 5'-GGATCCgacgatgacgataagCATG CTGAAGGGACC - $3^{\prime}$ (BanHI site underlined, enterokinase recognition sequence in small letters. and the $\mathrm{N}$-terminal region of GLP-I in boldface type). and the reverse primer was 5'-GA AATCTCGCTAGCTCCTCGGCC-3' (NheI site underlined and the C-terminal region of GLP-l in boldface type). GLP-I with an $\mathrm{N}$-terminal Ala was amplified with the forward primer 5'-GGATCCgacgatgacgataaggctGCTCATGCTGAAGGGA CC-3' (BanHI site underlined. enterokinase recognition sequence in small letters, Ala double underlined. and the N-terminal region of GLP-l in boldface type). GLP-I with an N-terminal Gly was amplified with the forward primer 5'-GGATCCgacgatgacgataagGGACATGCTGAAGGGACC-3' (BamHI site underlined, enterokinase recognition sequence in small letters. Gly double underlined and the N-tenminal region of GLP-l in boldface type). The PCR product digested with BamHI and NheI was subcloned into the pSGHV0-Fc vector. Accuracy of the fusion constructs in the expression vector was confirmed by DNA sequence analysis.

Expression of GLP-1/IgG-Fc fusion proteins. Chinese lamster ovary $(\mathrm{CHO})-\mathrm{K} 1$ cells were transfected with wild-type or modified GLP-1//gG-Fc plasmid using polyethyleneinine according to the mamufacturer's instructions. The 3,6.10-days conditioned mediun were combined for protein purification.

Purification of GLP-1/IgG-Fc fusion proteins. Protein purification was carried out using AKTA Prime (GE Healthcare). 5-mL HisTrap FF column was equilibrated with buffer A (20 mM sodium phosphate. $0.5 \mathrm{M} \mathrm{NaCl}, \mathrm{pH} 8.0$ ). Following sample loading, the colunn was washed with buffer $A$ and eluted with Buffer B (1 M imidazole) with 2 - $50 \%$ gradient at $5 \mathrm{~mL} / \mathrm{min}$. After elution, proteins were concentrated using Vivaspin 20 (GE Healthcare). The fusion proteins were incubated with enterokinase (EKMax. Invitrogen) for 16 hours at $25^{\circ} \mathrm{C}$, and the enzy me was removed with EKAway affinity resin (Invitrogen). Cleaved fusion proteins were separated by Protein $A$ 
column chromatography (GE Healthcare). and neutralized with $1 \mathrm{M}$ Tris $\mathrm{Cl}, \mathrm{pH} 8.0$. Fusion protein in each fraction was separated by SDS-PAGE and stained by Coomassie staining solution and silver nitrate. respectively. The expression of fusion protein was also identified by immunoblotting with monoclonal antibody to GLP-1 followed by detection with ChemiDoc XRS (Bio-Rad). Each band was analyzed using Quantity One software (Bio-Rad).

Degradation by DPP-IV enzyme. AMC-conjugated peptides were synthesized. buffer exchanged with acetate buffer. and lyophilized. $100 \mu \mathrm{M}$ of AMC-conjugated peptide in $500 \mu \mathrm{L}$ of $50 \mathrm{mM}$ Tris.HCl. I mM EDTA. pH 8.0 was incubated with DPP-IV for 1 hr at $37^{\circ} \mathrm{C}$. The fluorescence change was measured using AMICO-Bowman Series 2 (AB2) Spectrofluorometer between 365-535 nm upon excitation at $350 \mathrm{~nm}$. Data were plotted using GraphPad Prism software.

IRS-2 induction. INS-1 cells were grown in RPMI 1640 with $10 \%$ FBS at $37^{\circ} \mathrm{C}$ with $5 \% \mathrm{CO}$. INS-1 cells were treated with $50 \mathrm{nM}$ GLP-I or GLP- $1 / \mathrm{IgG}-\mathrm{Fc}$ fusion proteins. Cells were washed with cold PBS and lysed in lysis buffer at $4{ }^{\circ} \mathrm{C}$ for 1 hour. Cells were harvested at $12,000 \times \mathrm{g}$ for $10 \mathrm{~min}$ and the supernatant was collected. $30 \mu \mathrm{g}$ of cell lysates were separated by SDS-PAGE in a $10 \%$ separation gel and transferred onto nitrocellulose membrane. The expression of IRS-2 was identified by immunoblotting using polyclonal antibody to IRS-2

Acknowledgments. We thank Dr. Tai Jong Kang for suggestions on fluorescence measurements. This work was supported by the 2009 Hannam University Research Fund (to H. $-\mathrm{S}$. C.). This work was also supported by Alteogen Inc.

\section{References}

1. Doyle, M. E; Egan, I. M. Phamacol. Ther: 2007, 113, 546.
2. Deacon, C. F., Iohnsen, A. H.: Holst, I. J. J. Clin. Endocinol. Metab. 1995, 80,952.

3. Eng, J:: Kleinman, W. A.; Singh, L.; Singh, G.: Raufman, J. P. J. Biol. Chem. 1992, 267,7402.

4. Parkes, D. Todka, C.; Smith P.; Navak, S :- Rinehart L.; Gingerich, R.; Chen, K:; Young, A. Dnig. Dev. Res. 2001, 5t, 260.

5. Lin, H. K.: Green, B. D.: Gault, V. A.; McCluskey, J. T.: McClenaghan, N. H.; O'Harte, F. P.; Flatt, P. R. Cell Biol. Int. 2004, 28 , 69.

6. Green, B. D.; Mooney, M. H.: Gault, V. A.: Irwin, N.; Bailey, C. I.: Harriott, P.; Greer, B.; O'Harte, F. P.: Flatt, P. R. J. Endocinol. 2004, 180,379

7. Deacon, C. F: Knudsen, L. B; Madsen, K.; Wiberg, F. C.; Tacobsen, O.: Holst, I. I. Diabetologia 1998, 11, 271.

8. Burcelin, R.: Dolci, W.: Thorens. B. Metabolism 1999, 48. 252.

9. Gallwitz, B.; Ropeter, T:; Morys-Wortmann, C.: Mentlein, R.; Siegel, E. G.; Schmidt, W. E. Regul. Pept. 2000, 86, 103.

10. Xiao, Q; Giguere, J.; Parisien, M.; Jeng. W: St-Pierre, S. A.; Brubaker, P. L.; Wheeler, M. B. Biochemism, 2001, $40,2860$.

11. Green, B. D.: Gault, V. A.: Irwin, N.: Mooney, M. H.; Bailey, C. T.; Harriott, P.; Greer, B.; Flatt, P. R.; O'Harte, F. P. Biol. Chent. 2003, 384,1543

12. Hinke, S. A.; Manhart, S.: Kulu-Wache, K.: Nian, C.: Demuth, H. U.: Pederson, R. A.; McIntosh, C. H. J. Biol. Chem. 2004. 279,3998

13. Baggio, L. L.; Huang, Q; Brown, T. J; Drucker, D. T. Diabetes 2004, 53, 2492.

14. Kumar, M.; Hunag, Y.: Glinka, Y.: Pruddhomme, G. J.; Wang, Q. Gene Ther 2007, 14, 162 .

15. Pauly, R. P; Rosche, F.; Wermann, M.; McIntosh, C. H: Pederson, R. A.; Demuth, H. U. J. Biol. Chem. 1996, 271, 23222.

16. Smith, R. E.; Reynolds, C. J.; Elder, E. A. Histochem J. 1992, 24, 637.

17. Niessen, M. Arch. Phvsiol. Biochent. 2006, 112,65.

18. Lopez de Maturana, R.; Willshaw, A.; Kuntzsch, A.; Rudolph, R.; Donnelly, D. J. Biol. Chem. 2003, 278, 10195

19. Runge, S.: Thogersen, H.; Madsen, K.: Lau, J.: Rudolph, R. $J$. Biol. Chem. 2008, $283,11340$.

20. Leahy, D. . .; Dann, C. E., 3rd; Longo, P.; Peman, B.; Ramyar, K. X. Protein Expr: Purtf. 2000, 20,500. 